only those with non-small cell cancer were more likely to receive a form $\left(16 / 22\right.$ vs $\left.30 / 78 \chi^{2}=8.1, p=0.004\right)$. Only three patients with a clinical diagnosis and three with small cell received forms (both $\mathrm{p}=\mathrm{NS}$ ). Overall median survival was 216 days [IOR 405], with 57 alive at 6 months and 33 at 1-year. Median survival was 193 [268] days for those with DS1500 compared with 224 [458] in the remainder $(p=N S)$, and $31(57 \%)$ of those who died within 6 months did not benefit from early DS1500 status.

Conclusion While the DS1500 use was appropriate, the number identified represented less than a half of those who died within 6 months of presentation, and those with the poorest prognosis (small cell type or a clinical diagnosis) did not benefit the most. It seems we are missing an opportunity to support this unfortunate group of patients at the time of their greatest need.

\section{P159 RATE OF CHEST X-RAYS (CXR) TWELVE MONTHS PRIOR DIAGNOSIS OF LUNG CANCER}

doi:10.1136/thoraxjnl-2011-201054c.159

A Dwarakanath, M E J Callister. Leeds Teaching Hospitals NHS Trust, Leeds, UK

Introduction UK 5 year survival from lung cancer lags behind other developed nations, and one suggested reason is late stage at diagnosis. Efforts are therefore underway to encourage patients to present earlier to primary care with chest symptoms, and to encourage earlier referral in primary care for CXR or clinic review. Stage at presentation varies between geographical areas, suggesting variability in referral even within UK regions. The reasons underlying this variability are unknown, but one possible explanation could be different patient behaviours or clinical practice in primary care.

Aim To analyse the number of CXRs done 12 months prior to a confirmed diagnosis of lung cancer according to stage at presentation. Method We reviewed all patients with lung cancer discussed at the Lung MDT between December 2008 and May 2009. Cases of Small Cell Lung Cancer were excluded. The stage (IASLC 6th system), and number of CXRs performed within 12 month prior to diagnosis were recorded. Numbers of CXRs for each group were compared using Kruskal-Wallis test with Dunn's post-test comparison.

Results 223 NSCLC (stage $1 \& 2=61$, stage $3=61$, stage $4=101$ ) and 32 SCLC (limited-12 \& extensive-20) were diagnosed. Median, IOR and range of number CXRs in the previous 12 months are displayed in Abstract P159 table 1. Patients presenting with stage IV lung cancer had undergone significantly fewer CXRs in the year prior to diagnosis compared to patients diagnosed with stage I/II lung cancer $(p<0.05)$ and those diagnosed with stage III disease $(p<0.05)$. There was no significant difference between the stage I/II and stage III disease.

Abstract P159 Table 1

\begin{tabular}{llll}
\hline & Median & IQR & Range \\
\hline I\&II $(\mathrm{n}=61)$ & 2 & $0-3$ & $0-14$ \\
III $(\mathrm{n}=61)$ & 2 & $1-3$ & $0-12$ \\
IV $(\mathrm{n}=101)$ & 1 & $0-2$ & $0-7$ \\
\hline
\end{tabular}

Conclusion Patients with late stage disease (Stage IV) appear to have fewer CXRs in the year prior to diagnosis than patients presenting with earlier disease. This may represent a reluctance to seek medical review for persistent respiratory symptoms, or reluctance among GPs to refer for CXR. Ongoing analysis is investigating rates of GP consultation and antibiotic prescription among these patients to try to discriminate between then possible explanations.

\section{P160 TURNING ROUND LUNG CANCER CARE IN LIVERPOOL: A 15-YEAR AUDIT}

doi:10.1136/thoraxjnl-2011-201054c.160

A Nazir, T A Aljemmali, S M Kazmi, D Nazareth, K Mohan, C Smyth, M Ledson, M Walshaw. Liverpool Hear and Chest Hospital NHS Foundation Trust, Liverpool, UK

Background Liverpool has the highest incidence of lung cancer in England and Wales, and a citywide audit in 1996 identified significant deficiencies in the secondary care sector management of suspected cases. As a result of this, major reforms were made to benefit the majority of Liverpool residents in 1999, including the collaboration of competing hospitals to provide a unified service, a dedicated one stop rapid access clinic with same-day CT and bronchoscopy facilities, the employment of lung cancer specialist nurses, and parallel clinics for speedy onward referral. We have continued to refine this service, the largest in the region, and wished to compare outcomes to date.

Methods We compared the results of the service at three time points: at the 1996 audit, immediately after the inception of the service in 2001 and in 2010.

Results The results are summarised in the Abstract P160 table 1. In addition by 2010, two thirds had CT and bronchoscopy (6 EBUS) on the same day as their rapid access clinic appointment, and 48 underwent EBUS (mean wait 5 days). The average waiting time for PET scan in 2010 was 10 days.

\section{Abstract P160 Table 1}

\begin{tabular}{llll}
\hline Year & $\mathbf{1 9 9 6}$ & $\mathbf{2 0 0 1}$ & $\mathbf{2 0 1 0}$ \\
\hline Total no & 123 & 134 & 408 \\
Mean time to see chest physician (days) & 14.8 & 4.4 & 4.0 \\
Number presenting via A\&E (\%) & 67 & 42.5 & 38 \\
Proportion undergoing Bronchoscopy (\%) & 54 & 85.8 & 88.7 \\
$\begin{array}{l}\text { Average time interval to bronchoscopy } \\
\text { (days) }\end{array}$ & 14.6 & 4.4 & 1.23 \\
$\begin{array}{l}\text { No of patients undergoing staging CT scan } \\
\text { (\%) }\end{array}$ & $60(\mathrm{~N}=74)$ & $83.5(\mathrm{~N}=112)$ & $99.2(\mathrm{~N}=405)$ \\
Histological diagnosis achieved (\%) & $61(\mathrm{~N}=75)$ & $75.3(\mathrm{~N}=104)$ & $80.85(\mathrm{~N}=330)$ \\
Surgical resection rate (\%) & $6.50(\mathrm{~N}=8)$ & $8.20(\mathrm{~N}=11)$ & $16.8(\mathrm{~N}=69)$ \\
\hline
\end{tabular}

Conclusion This study confirms that the care of lung cancer patients in Liverpool has improved since the introduction of these new services, which we encourage other units to emulate.

\section{P161 COMBINED 18F-FDG PET/CT AS PART OF A SURVEILLANCE PROGRAMME OF PATIENTS WITH NEWLY DIAGNOSED PRE- INVASIVE ENDOBRONCHIAL LESIONS DETECTS SYNCHRONOUS LUNG CANCERS}

doi:10.1136/thoraxjnl-2011-201054c.161

${ }^{1} \mathrm{~L} J$ E Smith, ${ }^{2} \mathrm{~K}$ Kayani, ${ }^{2} \mathrm{~J}$ Bomanji, ${ }^{2} \mathrm{~A}$ M Groves, ${ }^{3} \mathrm{~B}$ Carroll, ${ }^{3} \mathrm{~N}$ Navani, ${ }^{3} \mathrm{~J}$ P George, ${ }^{3} \mathrm{~S}$ M Janes. ${ }^{1}$ University College Hospital, London, UK: ${ }^{2}$ Institute of Nuclear Imaging, UCL, London, UK; ${ }^{3}$ Centre for Respiratory Research, UCL, London, UK

Background Patients with bronchial pre-invasive lesions represent a significant management challenge due to the risk of lung cancer both at the site of known dysplasia and at remote sites within their lungs. The role of combined positron emission tomography/CT (PET/CT) in those patients is unknown.

Aims To evaluate the diagnostic and clinical utility of 18F-FDG PET/CT in a surveillance programme for patients with pre-invasive endobronchial lesions. This was defined as the ability of abnormal 18F-FDG uptake to detect invasive bronchial carcinomas adjacent to known pre-invasive lesions or at remote sites in the lung. The 